\title{
pro.posições
}

$e$-ISSN 1980-6248

http://dx.doi.org/10.1590/1980-6248-2016-0170

RESENHAS

\section{PEREIRA, Vilmar Alves. (2016). Ecologia Cosmocena: a redefinição do espaço humano no cosmos. Juiz de Fora: GARCIA edizioni. 98 pp.}

João Fernando Ferrari Nogueira (i)

(i) Universidade Federal do Rio Grande, Rio Grande, RS, Brasil. http://orcid.org/0000-0003-2482-

8614.joaonogueira@inventati.org.

É do horizonte atual de múltiplas crises que Vilmar Alves Pereira - filho de pequenos agricultores, professor do Instituto de Educação da Universidade Federal do Rio Grande e líder do grupo de estudos de fundamentos da Educação Ambiental e Popular - propõe a Ecologia Cosmocena, tanto como fundamento para a Educação Ambiental, quanto como alternativa viável para repensar as relações entre seres vivos e não vivos no planeta. A forma como ele se apresenta na orelha do livro, do modo que descrevi aqui, já traz características de sua proposição.

Trata-se de um esforço compreensivo inicial, a partir das múltiplas dimensões da humanidade, apreendidas em sua trajetória de vida e de formação na Filosofia. Essa trajetória inicia-se num olhar metafísico para, com as vivências do mundo da vida, avançar à fecundidade dos estudos de Habermas e Gadamer na Hermenêutica Filosófica. Mas recentemente, esses estudos apontam para um deslocamento no campo dos fundamentos da Educação Ambiental, da epistemologia para a ontologia. Logo, sua proposta decorre dessa necessidade hermenêutica de reposicionar a relação humanidade-natureza.

O autor, após a apresentação, inicia a obra definindo o horizonte de discussão, que, como mencionado, envolve múltiplas crises. As assinaladas por ele são: a crise civilizatória em Leff (2006), a crise de sentido em Zohar e Marshall (2012), a crise entre ciência e religião a partir de Wilson (2008) e, nesta conjuntura, a crise socioambiental como descrita em Boff (2012), Loureiro (2004) e outros autores, principalmente da Educação Ambiental. Segundo ele, todas essas crises relacionam-se a uma crise do paradigma metafísico que perpassa a modernidade, e agora se torna incapaz de sustentar verdades pretensamente absolutas e teleologias seguras. 


\section{pro.posições}

$e$-ISSN 1980-6248

http://dx.doi.org/10.1590/1980-6248-2016-0170

Aqui o entendimento de Habermas é fundamental para compreender o esgotamento da filosofia da consciência, com a crise desse paradigma, e a emergência das ciências históricohermenêuticas em deslocamento para a filosofia da linguagem. É do agir comunicativo (2001) e da emergência do pensamento pós-metafísico (2002) de Habermas, que o autor funda as bases da Ecologia Cosmocena, na então chamada Racionalidade Ambiental Pós-metafísica, que é mais desenvolvida no capítulo seguinte da obra.

Combinando a racionalidade ambiental de Leff (2006) com o horizonte pós-metafísico, reconhece a dimensão plural da Educação Ambiental, em sua multiplicidade de formas, sentidos e teorias, destacando a relevância dos contextos e da linguagem, como já mencionado, o que também modifica a relação sujeito-objeto da modernidade para uma relação de intersubjetividade (sujeito-sujeito). A influência habermasiana é destacada na mudança da relação teoria e prática, em que esses horizontes se fundem. Aqui o autor destaca novamente o fenômeno de deslocamento que observa na Educação Ambiental, da epistemologia para uma ontologia ambiental hermenêutica, que se apresenta mais abrangente em termos de sentido do que a epistemologia, o que permite inclusive o reconhecimento e o acolhimento de crendices, adotando uma dimensão espiritual do ser humano, talvez o ponto que fomentará mais críticas ou resistência à teoria. Destaco a importância da leitura da obra para que essas críticas contribuam no aprimoramento da proposta.

Dessa ontologia e da racionalidade ambiental pós-metafísica alargadas de sentido surgem desafios, aos quais a Ecologia Cosmocena buscará contribuir com sua reflexão. Alguns deles, mencionados pelo autor, são: a concepção de uma Educação Ambiental integral (ou seja, que considere as mais diversas dimensões dos seres); o reconhecimento de outridades e saberes negados e marginalizados pelas epistemologias clássicas; a visão menos hierárquica e mais compartilhada dos conhecimentos; a relevância dos contextos e da linguagem que nos constitui; logo, a busca de intersubjetividade e consensos; a constatação de uma ontologia e uma epistemologia hermenêuticas como processos permanentes de ser, interpretar e compreender o mundo.

No capítulo seguinte o autor dedica-se finalmente a concepção de Ecologia Cosmocena, como alternativa viável para pensar as relações entre os seres, cuja ampliação de sentidos reposiciona o ser humano, não mais restrito ao conceito de sujeito moderno, vítima de crise de sentido existencial-ontológico e sim conectado com todo o cosmos. Reitera que essa 


\section{pro.posıções}

$e$-ISSN 1980-6248

http://dx.doi.org/10.1590/1980-6248-2016-0170

compreensão é resultado de seus estudos, que iniciam na filosofia grega, passando por Rousseau, Kant, Nietzsche, Freud, Rorty, Heidegger, Habermas, Gadamer e, nos últimos anos, por aproximações desses com os fundamentos da Educação Ambiental, a física quântica, a biologia e a ciência espírita.

A origem do termo Cosmocena, segundo o autor, é intuitiva e surge da popularização de uma teoria proposta por Paul Crutzen, vencedor de prêmio Nobel, de que os impactos negativos da intervenção humana fundam uma nova era geológica, a saber, Antropoceno. Assim, a Ecologia Cosmocena seria o contraponto necessário à lógica antropocena, e para tal a primeira se define a partir de oito teses.

A primeira tese trata da nova relação entre natureza e humanidade, com o reconhecimento da outridade da natureza, resultando numa relação intersubjetiva. Para destacar a intersubjetividade da relação natureza-humanidade, outro termo é cunhado: biopsicossocioambiespiritual (relacionando as dimensões biológicas, psicológicas, sociais, ambientais e espirituais). A segunda tese fala da necessidade da desaceleração do tempo, em termos conceituais e de percepção, como garantia da vida, destacando o que alguns autores chamam de presenteísmo, como a intensificação do presente vivenciado nas sociedades capitalistas modernas, bloqueando a criatividade e o cuidado, em sentido ético. A terceira tese propõe a sintonia com novas sabedorias, seja no acolhimento da abertura ontológica que já mencionei, seja no reconhecimento dos saberes tradicionais afastados pela epistemologia dominadora cartesiana. A quarta tese opõe, ao consumo desenfreado que esvazia de sentido a existência humana, o cuidado como reaprendizagem, já que, para Boff, o cuidado é um a priori ontológico dos seres humanos.

A quinta tese problematiza a importância que a tecnologia, em especial as redes sociais, adquiriu na sociedade ao propor a descolonização do mundo da vida, servindo-se dos conceitos da Teoria da Ação Comunicativa de Habermas, aliados aos alertas da liquidez das relações humanas na produção do sociólogo polonês Bauman. A sexta tese também decorre diretamente da abertura ontológica de sentidos para acolher a categoria da pluralidade, especialmente epistemológica, quando falamos da pesquisa científica, para o reconhecimento de que o mundo é diverso, e, portanto, deve ser livre de preconceitos. A sétima tese ensina que, mesmo neste horizonte cósmico, somos seres finitos e limitados, reivindicando que uma reavaliação da condição existencial humana é necessária e aqui apresenta parte do debate entre ciência e 


\section{pro.posições}

$e$-ISSN 1980-6248

http://dx.doi.org/10.1590/1980-6248-2016-0170

religião, como discussão profícua que, reconhecendo a incompletude da vida, não deixa de ganhar sentido ontológico.

A oitava e última tese apresenta o lugar da Educação Ambiental como espaço de reflexão crítica que pode contribuir com o desenvolvimento do ser humano na articulação de todas as teses, sendo praticada em todos os lugares possíveis e pensada para todas as pessoas, mas sempre em favor dos excluídos pelos próprios humanos. Ao fim do capítulo que apresenta as teses, o autor ressalta que a Ecologia Cosmocena não trata de uma nova metafísica e muito menos de uma visão harmônica e debilitada de mundo, mas, sim, de uma alternativa viável na luta pela vida digna, pela ampliação de sentidos e pela melhoria da convivência na relação do cosmos com a humanidade.

Dessa preocupação com a aplicabilidade da Ecologia Cosmocena, as oito teses desdobram-se, no quarto capítulo, em uma pedagogia com oito decorrências diretas das teses originais, a saber: aprendizagem humanística relacional, para o reconhecimento das outridades; aprendizagem como processo de valorização da vida, visando ao desenvolvimento integral dos processos cognitivos, afetivos, espirituais, estéticos e biológicos; aprendizagem como hermenêutica dos saberes não reconhecidos, para a valorização da linguagem na abertura da compreensão de vivências epistemológicas e ontológicas; aprendizagem do cuidado, como aquela condição primeira de humanidade que mencionei, envolvendo a chamada cultura da paz; aprendizagem dos saberes primevos, para valorizar nossas raízes socioculturais e descolonizar o mundo da vida da razão instrumental; aprendizagem com as diferenças, para o reconhecimento da pluralidade; aprendizagem transcendental, para a valorização da dimensão espiritual do ser humano diante de sua incompletude, para além de crenças ou ausência delas por parte dos pesquisadores, mas como busca de sentido ontológico, já que, para muitas pessoas, essa dimensão é parte fundamental de suas vidas; aprendizagem do ambiente inteiro, para superar a antiga separação da humanidade de todo o cosmos.

O quinto e último capítulo foi escrito em forma de carta aos amigos e amigas da obra, afastando-se de uma conclusão, por reconhecer a inconclusão em si mesma. Nela o autor reforça que se trata de uma Ecologia de forte caráter humanista e de valorização da vida, fruto de suas vivências com inúmeras pessoas em inúmeros projetos, às quais expressa sua gratidão, esta que também é um valor cosmoceno, segundo ele. Novamente se refere à obra como um paradigma em construção e sempre aberto a sugestões, e é neste sentido que espero que esta resenha 


\section{pro.posıções}

$e$-ISSN 1980-6248

http://dx.doi.org/10.1590/1980-6248-2016-0170

estimule a leitura da obra, fomentando contribuições com o desenvolvimento da Ecologia Cosmocena. A urgência da reflexão, para o autor, é de que, como seres cósmicos e abertos ao mundo, necessitamos desenvolver processos formativos que acima de tudo contribuam para a nossa ampliação de sentido da vida. A obra é indicada não apenas aos educadores ambientais, mas a todos os envolvidos ou interessados na área da Educação. 


\section{pro.posıções}

$e$-ISSN 1980-6248

http://dx.doi.org/10.1590/1980-6248-2016-0170

\section{Referências}

Boff, L. (2012). As quatro ecologias: ambiental, politica e social, mental e integral. Rio de Janeiro: Mar de Idéias.

Habermas, J. (2001). Teoría de la acción comunicativa. Madrid: Taurus.

Habermas, J. (2002). Pensamento pós-metafísico. Rio de Janeiro: Tempo Brasileiro.

Leff, E. (2006). Racionalidade ambiental: a reapropriação social da natureza. Rio de Janeiro: Civilização Brasileira.

Loureiro, C. F. B. (2004). Trajetórias e fundamentos da educação ambiental. São Paulo: Cortez.

Wilson, E. O. (2008). A criação: como salvar a vida na terra. São Paulo: Companhia das Letras.

Zohar, D., \& Marshall, I. (2012). Inteligência espiritual. Rio de Janeiro: Viva Livros.

Submetido à avaliação em 01 de dezembro de 2016; revisado em 04 de janeiro de 2017; aceito para publicação em 24 de fevereiro de 2017. 